\title{
The New Government Strategy for Higher Education in the Netherlands: An Analysis
}

\author{
F. A. van Vught, University of Twente, Netherlands
}

\begin{abstract}
In the Netherlands a new government strategy for higher education is emerging. This new strategy is presented by the Ministry of Education and Science as a development of more institutional self-regulation and a distancing of government from day to day higher education affairs. This article asks whether the Dutch Government is really allowing higher education institutions to become more autonomous. To answer this question two recent policy papers on higher education from the Ministry of Education and Science are analysed using a theoretical model of natural selection drawn from organisation theory.
\end{abstract}

\section{Introduction}

In the Netherlands a new government strategy towards higher education is being developed. The basic elements of this strategy, so it is claimed by the Dutch Ministry of Education and Science, are increased autonomy for the higher education institutions and the disengagement of government.

Several reasons for this new strategy can be adduced, including the ideological preferences of the current political coalition (in power since 1982), and the government's budgetary problems. These reasons are not typically Dutch. Similar circumstances can be found in many western countries. The attitude of the Dutch Government towards higher education, however, appears to be rather unique compared to the situation in, for example, the Federal Republic of Germany, France, or the United Kingdom.

As was first clearly indicated in the policy-paper Higher Education: Autonomy and Quality (Ministry of Education and Science, 1985) which is known by its Dutch acronym, HOAK, the Dutch government wants to develop the guiding principle of remote governmental control and enlarged institutional autonomy. The recently published Plan for Higher 
Education and Scientific Research (Ministry of Education and Science, 1987b), known by its Dutch acronym, HOOP, supports this picture. No longer is higher education to be regulated and steered solely by the central government. According to the Minister of Education and Science, all relevant parties in Dutch higher education will become involved in a dialogue concerning the future of Dutch higher education.

Bearing the above in mind, in this article the new government strategy towards higher education will be analysed. More specifically the question will be raised of whether government is really disengaging as it claims. The basic conceptions of the new government strategy, as presented in the Autonomy and Quality policy-paper (HOAK) and the second Higher Education Scientific Research Plan (HOOP) will be explored. To be able to judge these basic conceptions a theoretical model will be developed, which will be called the model of natural selection. This theoretical model will be used as the basis for a modest analysis which will result in the conclusion that the new Dutch government strategy towards higher education is a hybrid which may be interesting to watch in practice, but which is not very clear from a theoretical point of view (Florax and Van Vught, 1986).

\section{Two policy-papers}

In 1985 the Dutch Ministry of Education and Science published an important policy-paper, Higher Education: Autonomy and Quality (HOAK) in which a new strategy towards higher education was presented. The new attitude of the Ministry of Education and Science towards higher education in the Netherlands represents an important break with traditional government strategy which was one of detailed planning and control. The government tried to steer the higher education system with stringent regulations and extensive control-mechanisms. The government saw itself as an omnipotent actor, who could guide the higher education system according to its own objectives.

The new strategy appears to be an important change. By strengthening the autonomy of higher education institutions, the government claims to create fruitful conditions for the enlargement of the adaptive power and flexibility of higher education institutions to respond to the needs of society. By strengthening institutional autonomy, the government also aims to raise the level of quality and stimulate differentiation in the higher education system.

The new government strategy is based on the idea that the increase in institutional autonomy will result in the improvement in the performance of the higher education system. The higher education institutions will 
have more autonomy to shape their own activities. They will be allowed to take their own responsibilities in the fields of education and research. The detailed government regulations concerning these activities will be done away with.

The enlargement of institutional autonomy is assumed to result in a better adjustment to, and even an anticipation of, changing conditions in society. As a result of the enlargement of institutional autonomy the system as a whole is expected to become more effective in its reactions to the increasing turbulence in its environment and hence to become better suited to the rapidly changing demands of modern society. More autonomy at the institutional level is expected to result in more scientific and technological breakthroughs and in better educated professionals.

Another basic idea of the new strategy is that instead of attempting an $e x$ ante control of the performance of higher education institutions, an ex post evaluation of quality should be institutionalised. For this kind of ex post evaluation, the government claims to need a quality control system, consisting not only of the monitoring and evaluation activities of the institutions, but also of an 'independent' quality assessment by government (Ministry of Education and Science, 1985).

Recently the HOAK paper has been followed by another important policy document: HOOP, Plan for Higher Education and Scientific Research. This is the next - operational - step in the development of the new Dutch government strategy. In this a great deal of prominence is given to planning by means of dialogue. The dialogue is supposed to be based on objectives for the future as seen by both government and the higher education institutions. These objectives will be written down in the two central documents of the planning system developed as a consequence of the new strategy: the government plan (HOOP) and the development plans of the institutions.

The HOOP document will contain all the government higher education documents previously appearing separately. It offers an image of the future of the higher education system as desired by government. The institution's development plans are to be a reflection of the intentions of the institutions, of the influences from their environment and of their internal activities and developments.

The new planning system has a two-year cycle, with the HOOP document being published in the first, and the institutional development plans in the second year. The first (draft) HOOP document was published in September 1987 and the first development plans appeared in the spring of 1988 .

In both the HOAK and the HOOP policy-papers, many details can be 
found concerning the intended interactions and communications in the higher education system in the near future. To provide an impression of the new Dutch strategy, some of these details will be presented in the next section of this article. They concern the most important aspects of the government's philosophy and the methods chosen to steer and influence the system.

\section{Steering philosophy and steering instruments}

In its new strategy towards higher education the Dutch government approaches the concept of steering the higher education system using the idea of 'steering networks'. A steering network is defined as a combination of actors (particularly the Ministry of Education and Science and the higher education institutions), of issues at which the steering activities are aimed and of instruments which are used by the actors to try to reach their objectives. It is the opinion of the Ministry that, as a consequence of the new strategy, the characteristics of the steering networks will change. In the HOOP document the expected and desired changes are shown diagramatically as in Figure 1.

As may be seen from Figure 1, the most important feature of the steering
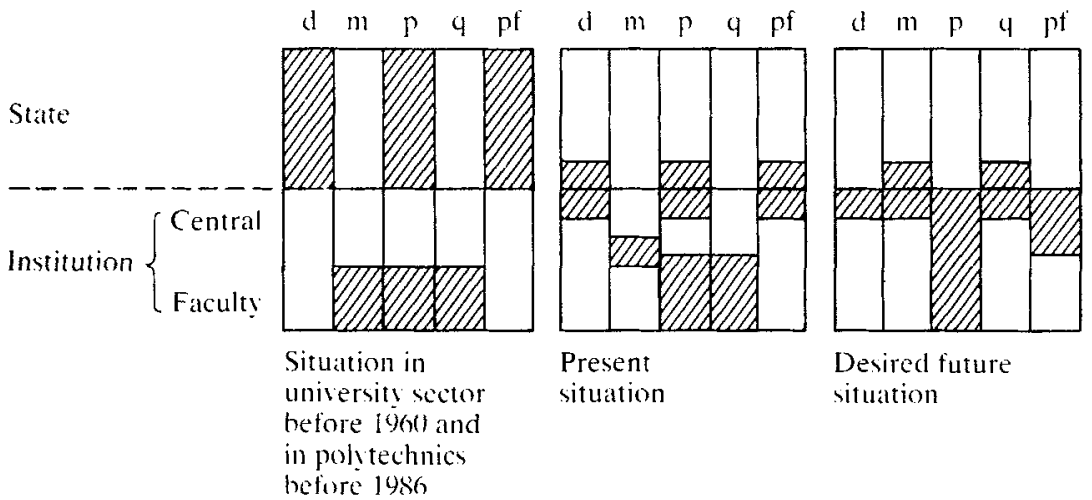

$$
\text { Key: } \begin{aligned}
d & =\text { design } \\
m & =\text { mission statement } \\
p & =\text { instiutional processes } \\
q & =\text { quality } \\
p f & =\text { production factors }
\end{aligned}
$$

Figure 1: Activitics and actors in steering networks

Source: Datch Ministry of Education and Science, (1978b. p.85). 
networks concern the design of the system in general, the institutional mission statements, the content and form of institutional processes, the control of the quality of institutional processes, and the decisions on production factors (personnel policies and the like). The government emphasis at the moment is on the design of the system, the content and form of institutional processes, and production factors. According to the Ministry, the new strategy entails a change of emphasis in which government wants to limit its activities to influencing the development of institutional mission statements, as well as to the use of the judgements from the quality control system (which to a large extent still has to be established).

Let us look at these two issues in more detail. Until now the development and formulation of an institutional mission statement was hardly a subject of governmental concern. Some higher education institutions had them, others did not; but in either case the government was uninterested. However this will change with the advent of the new strategy, especially through the introduction of the so-called 'mission budget'.

Presently the nature of the lump sum assigned to the higher education institutions consists of an education budget and a research budget. To these two budgets the new 'mission budget' will be added. The 'mission budget' will be part of the future institutional lump sum. It is meant to provide institutions with resources to finance innovations; and these innovations should be an important element in the strategic management activities of institutions.

In the new government strategy, the development of an institutional strategic policy is considered to be a prerequisite to reaching a more market-oriented higher education system. The size of a mission budget assigned to an institution will be determined on the basis of detailed government regulations (Ministry of Education and Science, 1987b). These regulations will amongst other things be based on the use of performance indicators.

The idea of the assessment of the performance of the higher education institutions appears to be a cornerstone of the new strategy. In the eyes of government, its decisions with regard to the institution will in the future to a large extent be based on judgements concerning institutional performance. The government believes that this will have to be assessed through a quality control system. One of the basic new elements of the strategy is the wish to develop such a system.

Until now the assessment of an institution's performance has primarily been an informal one. Government tried to control the inputs and 
processes of the universities' educational programmes by means of the 'Academic Statute'; but neither educational, nor other output evaluations have been carried out. Performance assessment was mainly a task of individual staff-members making judgments about their own activities. Systematic, regular, collaborative assessments of the academic programmes and services of higher education institutions have never been a characteristic of Dutch higher education. The Ministry has indicated that this will have to change.

The representative bodies of the Dutch institutions, the VSNU, (Vereniging van Samenwerkende Nederlandse Universiteiten, or Association of Co-operating Dutch Universities) for the universities and the HBORaad (Hoger Beroepsonderwijs-Raad or Council for Higher Vocational Education) for the polytechnics, have taken up the challenge of government to develop a quality control system. Each of these two bodies is starting from a different perspective. The VSNU has developed a system with an emphasis on the use of external visitors, the HBO-Raad has started with self-evaluation projects. Next to this, the VSNU is focusing on the review of educational programmes of subject disciplines, while the HBO-Raad is aiming at institution-wide evaluations.

In spite of these efforts, however, the government has set up an inspectorate for higher education to monitor the performance of institutions.

According to the Ministry, one of the important functions of the quality control system must be to permit comparison between institutions. Performance indicators should make this comparability possible. They will serve as operational instruments for four important functions in the Dutch higher education system, namely an evaluation function, a monitoring function, a dialogue function, and a funding function. Concerning the evaluation function, performance indicators can show to what extent chosen goals have been achieved. As regards the monitoring function, they make it possible to signal relevant developments and/or trends. As far as the dialogue function is concerned, the indicators can be used as an objective basis of information. With respect to the funding function, there can be a direct link between the indicators and the budget assigned to an institution (Ministry of Education and Science, 1987b, p 106).

Both the 'mission budget' and the use of performance assessments make clear that the Ministry of Education and Science is developing steering instruments which will play an important role in the dynamics of the Dutch higher education system in the near future. Government claims that these instruments form a consistent part of their recently developed strategy. 
In the following paragraphs an attempt will be made to judge the new strategy from a theoretical point of view. To be able to perform this task a theoretical model will be developed, which can be used as a tool for analysing the dynamics of a higher education system.

\section{The 'natural selection model' as a tool for analysis of higher education system dynamics}

In terms of systems theory, higher education systems are open systems. They receive inputs from their environment (students, financial resources) and transform these inputs into outputs (students finishing their studies, research results, etc.).

In systems theory the concept of 'environment' is of great importance. Recent reflections in organisation theory about organisations as open systems also take this concept as a theoretical starting-point (Astley and Van de Ven, 1983). The basic idea in the literature is that complex processes of change in open systems can be explained by the processes of interaction between systems and their environment. One of the theoretical models used in this literature is the model of natural selection.

In the natural selection model the assumption is made that the interaction between an organisation and its environment will let certain types of organisations survive, leaving other types of organisations to die. The chances for survival of an organisation are greater the more this organisation fits the specific characteristics of an environment (Aldrich, 1979; Aldrich and Pfeffer, 1976; Hannan and Freeman, 1977).

Like biological species, organisations are supposed to go through a three stage process: variation, selection and retention. The result of this process is that, in a competition for scarce resources, some organisations will and others will not be able to fit the characteristics of an environment.

The phase of variation concerns the production of diversity in a system or an organisation. The greater the diversity in a system, the more chances there are for a successful answer to the criteria that the environment will use for selecting surviving systems. Diversity in a system can be produced deliberately or by accident; it may be the result of a conscious planning effort or of an accidental adaptation. In higher education systems the diversity grows when the number of higher education institutions and/ or the number of educational programmes offered increase.

The phase of selection concerns the process in which some organisations (as part of a system) appear to fit an environment. The selection takes place as a process of competition for scarce resources. Surviving organisations will be able to capture more of these resources than failing 
organisations. In higher education systems the crucial resource categories are the number of students and the amount and importance of research projects. Both these categories can provide a higher education institution with the financial resources it may need to be able to survive.

Retention is the process in which a surviving organisation is able to maintain itself over time. An organisation which was successful in a certain environment may remain successful as long as the environment does not change. When drastic changes take place in the environment, the organisation will again be faced with the question of how to respond to the new circumstances. Seen from the perspective of the natural selection model, higher education institutions often can, but sometimes cannot, adapt themselves to new environmental circumstances. In these latter cases those institutions will disappear.

The process of variation, selection and retention offers an evolutionary perspective on the system dynamics of higher education. In this perspective higher education institutions try to find themselves an evolutionary 'niche' in which they hope to be able to survive. A 'niche' can be interpreted as a set of conditions in which evolutionary processes take place. The institutions that have chosen a niche in which they appear to fit, will survive. The institutions that have chosen a niche which appears not to be suited to them will find out that their survival is threatened and that they will have to try to find another niche.

The system dynamics of higher education thus result in a specific kind of co-ordination. Co-ordination in this sense is not a centrally planned and implemented policy from above. It rather is a co-ordination without a coordinator (Wildavsky, 1979), and a result of the choices of the individual institutions. Higher education institutions will try to adapt themselves to changing circumstances. Given the boundaries of the competition for scarce resources, a structural order of specialisations will arise.

The natural selection model offers an interesting theoretical perspective for the analysis of the new governmental strategy of more institutional autonomy which is developing in the Netherlands. In the next section a modest version of such an analysis is presented.

\section{A combination of two fundamentally different models}

The new Dutch government higher education strategy incorporates some elements of the natural selection model. But it certainly is not in complete accordance with this model. It also includes elements of the traditional strategy of detailed planning and control.

The new strategy therefore can be characterised as a 'species of a half- 
way house between out-and-out dirigisme and integral institutional autonomy' (Neave, 1986). In the new strategy, the institutions have their own autonomy, but government has the power to influence their behaviour. Higher education institutions are confronted with more freedom, but this freedom is only a freedom to act according to the wishes of government. The newly emerging strategy appears to be a combination of two different conceptions of system dynamics.

If the natural selection model were indeed the theoretical basis of the government's attitude towards higher education, the fundamental general starting point for implementing it would have to be to accept and, if necessary, to optimise the working of the market-mechanism in higher education.

According to the natural selection model, a higher education system should be characterised by as complete a competition as possible. The 'producers' of higher education (the institutions) should compete for the favours of the consumers (e.g. students choosing an education; organisations giving out contracts for research projects). Every producer may try to find his own specialised niche while offering his goods in the market. But he may not try to control the market by forming a monopoly or a oligopoly. Competition is a crucial characteristic of the natural selection model.

The role of government in this model is to try to guarantee competition. On the one hand it is a task of government to protect the sovereignty of the consumers. On the other hand government should prevent the formation of monopolies and oligopolies. Co-ordinating the system or trying to optimize its performance is not an aspect of the role of government in this model.

The new Dutch government strategy, as presented in the HOAK and the HOOP policy-papers, shows quite another stance. Certainly, in this strategy the autonomy of the producers of higher education is increased and the competition between these producers is stimulated. As such the new strategy is in line with the natural selection model.

But in the new strategy, government is not mainly the protector of the sovereignty of the consumers and the fighter of monopolies and oligopolies. Government also tries to steer the higher education system from an Archimedical position. Government seeks to set 'overall targets' for the higher education system and influences the behaviour of the institutions to try to reach these targets. By doing this, however, government has to restrict the behaviour of the higher education producers. Certain forms of behaviour by the institutions cannot be allowed. And because of such restrictions, government creates a situation in which the institutions cannot develop certain adaptations to their 
environment. Because government wants to co-ordinate and steer the system from its own position, it will have to exclude some forms of adaptive behaviour by the institutions.

In the new strategy the institutional autonomy is restricted. Higher education institutions may operate as self-steering organisations to the extent government lets them. The natural selection model however assumes a maximum autonomy for the organisations in a system. Such a maximum autonomy is judged to be necessary because organisations are only thought to be able to find a vital evolutionary niche when they can decide themselves which forms of adaptive behaviour they should develop. The more this autonomy is restricted, the less an organisation will be able to find a successful adaptation to its environment.

The three phase process of variation, selection and retention can only partly take place in the new Dutch regime. Higher education institutions may have more autonomy than they used to have, but the dynamics of the higher education system in this strategy are restricted by the co-ordinating and steering activities of government. The co-ordination in the higher education system is not a 'co-ordination without a co-ordinator'. The specialisations in the system and the structural order therefore can only partly be the result of the institutional profiles which are being developed as the institutions try to find their own niches. The structural order and the specialisations in the system are to a large extent an outcome of the various decisions and actions of government, aimed at the optimisation of the system from the government's point of view.

The fact that the new government higher education strategy has two different faces also come to the fore, when attention is paid to the steering instruments which are being developed by the Ministry. It appears that, while on the one hand it is stated that the institutions are responsible for all the activities with the sectors ${ }^{\star}$ assigned to them (by government!), government on the other hand indicates that all the institutional activities should in one way or another match governmental ideas and intentions with respect to the desirable development of the higher education system. Deviating activities will have to be adjusted and missing activities will have to be set up. If institutions are taking no such measures government can interfere with the help of the newly developed instruments.

Both the 'mission budget' and the use of performance assessments will enable government to influence the behaviour of the higher education institutions. The 'mission budget' can be used to try to force the

* In the HOOP-document for higher education as a whole nine different sectors are distinguished, namely Arts, Law, Economy, Health, Behaviour and Society, Technique, Education, and Agriculture (Ministry of Education and Science, 1987b). 
institutions to develop the profiles government thinks to be necessary. As already indicated, these governmental attempts to influence and control the development of institutional missions restrict the institutions in establishing adaptive and flexible relationships with their environment. These attempts are therefore contradictory to the natural selection model.

The use of performance assessments also gives government the power to influence the behaviour of the institutions according to government wishes and opinions. The quality control system, especially as it is proposed by the Ministry of Education and Science, contains elements of the natural selection model as well as characteristics of the traditional government planning and control strategy. Institutions themselves are responsible for the development of a system in which the measuring of quality can take place. This implies self-assessment processes at the levels of the discipline and the sector. For the time being neither the inspectorate, nor any other government body will be directly involved in the measuring of quality. Steering on the basis of performance indicators will, however, to a large extent be the responsibility of government. Government will make decisions, especially with respect to the reallocation of funds, on the basis of the results of institutional self-evaluation processes. In this respect it will be the Ministry of Education and Science which will determine what quality of higher education is and how institutional performance should be assessed. The institutions will be allowed to measure their performance, but government will control the development of the system on the basis of quality.

Again it can be concluded that the government's attitude towards the organisation of the quality control system shows the combination of two theoretical models: the traditional model of planning and control, and the model of natural selection. Government claims to know the societal goals and it wants to represent the public interest. It is not clear, however, what the public interest is. It also remains unclear why an indirect representation of societal goals should be preferred to the possibility of a situation with direct relationships between higher education institutions and their relevant societal environments. This latter situation would be in accordance with the theoretical model of natural selection. It would enable the institutions of higher education not only to assess their own performance, but also to make their own decisions on the basis of the outcomes of these assessments. It would allow the institutions to try to find their evolutionary 'niches' and it would imply a system dynamics of higher education in which the co-ordination is a result of the choices of the consumers and producers of higher education. In the quality control system proposed by government the adaptive behaviour of the institutions 
is limited by the government's wishes and opinions. Government has chosen to develop a new strategy towards higher education which is a combination of two different theoretical models.

\section{Conclusion}

In this article the new emerging governmental strategy towards higher education in the Netherlands has been discussed. This new strategy is presented by government as a development towards more institutional self-regulation and a disengagement of the Ministry of Education and Science. The question has been raised whether in this new strategy the Dutch Government is really allowing the higher education institutions to become more autonomous. To answer this question the recent policy papers on higher education from the Ministry of Education and Science were analysed, using the theoretical model of natural selection.

Looking at the various proposals in both the HOAK policy paper (Ministry of Education and Science, 1985) and the HOOP planning document (Ministry of Education and Science, 1987), the conclusion can be drawn that the new Dutch government strategy towards higher education is a combination of two fundamentally different theoretical conceptions. In this strategy, aspects of the classical model of detailed planning and control are combined with aspects of the natural selection model. In the years to come the behaviour of the Dutch higher education institutions will to a large extent still be determined by the wishes and opinions of government. The innovations in the policies and operations of an institution will mainly reflect the opinions and ideas of the Ministry, since the possibilities open to an institution to innovate depend on the assessment of its outputs, and on the willingness of government to tolerate or stimulate the kinds of outputs produced.

On the basis of the above it can be stated that the increased institutional autonomy which is proclaimed in the new government strategy is at best a dependent autonomy. Government is only partly disengaging.

\section{References}

Aldrich, H. E. (1979), Organizations and Environments (Englewood Cliffs, Prentice Hall).

Aldrich, H. E. and Pfeffer, J. (1976), Environments of Organizations, Annual Review of Sociology, 2, pp. 79-105.

Astley, W. G. and van de Ven, A. H. (1983), Central Perspectives and Debates in Organization Theory, Administrative Science Quarterly, 28, pp. 245-273.

Florax, R. J. G. M. and van Vught, F. A. (1987), Planmatige sturing of natuurlijke selectie?, Bijleveld, R. J. and van Vught, F. A. (Eds.), Sturing van het hoger onderwijs ('sGravenhage, VUGA). 
Hannan, M. T. and Freeman, J. (1977), The Population Ecology of Organizations, American fournal of Sociology, 82, pp. 929-964.

Kells, H. R. and van Vught, F. A. (1988), Theoretical and Practical Aspects of a Selfregulation and Quality Control System for Dutch Higher Education, Tijdschrift voor Hoger Onderwijs, 6, pp. 11-18.

Luttikholt, H. (1986), Universities in the Netherlands: In Search of a New Understanding, European fournal of Education, 21, pp. 57-67.

Maassen, P. A. M. (1987), Quality Control in Dutch Higher Education: Internal Versus External Evaluation, European Journal of Education, 22, pp. 161-171.

Ministry of Education and Science (1985), Nota Hoger Onderwijs: Autonomie en Kwaliteit, Tweede Kamer der Staten Generaal, Vergaderjaar 1985-1986, 19253, nrs. 1, 2('sGravenhage, Staatsuitgeverii).

Ministry of Education and Science (1987a), Schets betreffende de toekomst van het hoger onderwijs en wetenschappelijk onderzoek (Zoetermeer, Ministerie van Onderwijs en Wetenschappen).

Ministry of Education and Science (1987b), Hoger Onderwijs en Onderzoek Plan, deel 1: Kerndocument (Zoetermeer, Ministerie van Onderwijs en Wetenschappen).

Neave, G. (1986), On Shifting Sands: Changing Priorities and Perspectives in European Higher Education from 1984 to 1986, European fournal of Education, 21, pp. 7-25.

Vught, F. A. van (1985), Negative Incentive Steering in a Policy Network, Higher Education, 14 , pp. 593-616.

Wildavsky, A. (1979), Speaking Truth to Power: the Ant and Craft of Policy Analysis (Little, Brown and $\mathrm{Co}$ ) 